\title{
Assessing Dense Neighbourhood Sustainability for Daylight Performance: A Case Study of Beijing
}

\author{
Yingyi ZHANG ${ }^{1}$ and Yanghongwei NING \\ School of Architecture and Urban Planning, Beijing University of Civil Engineering \\ and Architecture, Beijing 10044, China
}

\begin{abstract}
Daylight is a valuable natural resource that has been related to space quality and sustainable development. With the increasing density of urban population and physical environment, current manual-based daylight analysis and assessment have limited capabilities for dense neighbourhood evaluation and fail to effectively quantify natural daylight in residential zones. This paper proposes a parametric-based modelling system that perform year-round daylight access in dense neighbourhoods. Neighbourhood samples of Beijing work as study cases. Methods include data integration and parametric modelling. Geographic and climate information, building geometries, and daylight performance are computed with the parametric-based modelling system. Experiments at various residential building cluster layouts demonstrate the usefulness of the proposed system. Results indicate that parametric technology can provide positive innovation for daylight performance evaluation and dense neighbourhood sustainability assessment.
\end{abstract}

Keywords. Dense neighbourhood, sustainability assessment, architectural and planning research

\section{Introduction}

Urban population is growing at a high speed recently particularly in developing countries and cities. According to the United Nations statement, the world's urban population will increase by 2.5 billion by the year 2050 [1]. The report of Demographia World Urban Areas of Wendell Cox Consultancy states that the population ratio of $15,000 / \mathrm{km}^{2}$ is the lower end of the high-density range [2]. Per this ranking, there are more than one hundred high-density cities around the world (2020). Most high-density cities are located in India and China.

Cities are currently witnessing vast population cluster in compact living places. The concentration of humans-in some cases judges as too high, in others not high enoughand the problems connected to this, have resulted in discussions on density [3]. Density begins with population but must move beyond it [4]. Except for population, dense community and neighbourhood identification also relates to buildings and perceived density [5]. Floor area ratio is one representative index for measuring building density. Crawford (2000) indicates that the floor area ratio of 1.5 is too high to create a pleasant

\footnotetext{
${ }^{1}$ Corresponding Author, Yingyi ZHANG, School of Architecture and Urban Planning, Beijing University of Civil Engineering and Architecture, Beijing 10044, China; Email: zhangyingyi@bucea.edu.cn.
} 
street space [6]. However, the value of 1.5 is usually exceeded in dense cities today. For example, the floor area ratio value of a dense neighbourhood in Beijing, China can get to 5 plus. Perceived density encompasses far more than just physical density [7-8]. In an urban environment, spatial density refers to the perception of density with respect to the relationships between spatial elements such as height, spacing, and juxtaposition [5]. The mechanisms for controlling interaction levels such as spacing, physical elements, territorial boundaries, hierarchy, the size and nature of the group involved, its homogeneity and rules for behaviour all affect the rates of social interaction [9]. While increasing dense communities and neighbourhoods bring effective public resource and infrastructure sharing, they also affect the comfortable habitation space and urban environmental quality. People's behaviour may change when their communities and neighbourhoods become intensive. This paper focuses on physical building density in neighbourhood to explore living environment sustainability. The dense of buildings directly produce an effect on the natural resources such as daylight situation and then the liveability of the urban environment.

Daylight is the combination of all direct and indirect sunlight during the daytime. The perception of daylight in a dense neighbourhood contains direct sunlight as well as sunlight reflections of terrestrial objects, like landforms and buildings. It is a valuable natural resource that has been linked to the quality of space, occupant health, and energy conservation by offsetting electric lighting and its impact on heating and cooling loads [10-14]. In former researches, daylight normally works as an indicator to support individual building design. Early in the design process, quick and simple models are often developed to examine, evaluate and discuss building design ideas [15-16]. Kvan indicates that models in the architectural design process, especially early on, tend to be diagrammatic or representative in nature and they develop along the design process [1617]. Researchers regard daylighting at various scales from architectural façade components to building cluster studies [18-19]. There is limited research on daylight analysis and parametric simulation in dense neighbourhoods from the perspective of urban environment well-being. Daylighting and access to direct sunlight are essential in dense neighbourhoods. Neufert Architects' Data and Lighting for Communal Residential Buildings declare that the floor plan and space orientation should consider the movement of the sun [20-21]. Increased urban density leads to a conflict between space-use efficiency and daylight access [22]. This conflict is especially relevant to residential architecture, as adequate access to daylight is directly associated with liveability and quality of life in a dwelling [22].

This leads to the question of how to rational assess of dense neighbourhood sustainability for daylight performance. Three dense neighbourhoods of Beijing work as study cases in this paper to explore the question. The neighbourhoods locate at Fuxing Road and Sanlihe East Road, Haidian District with dense residential buildings and various-scaled street stores. The reasons to choose these neighbourhoods contain two aspects. Firstly, they have similarities in location, climate, and building density. They can work as examples to assess daylight situations in different building layouts, arrangements, coverage ratio, and floor area ratio with the similar natural environment. Secondly, the selected neighbourhoods have typical conventional performance of residential zones of Beijing. They have houses, accommodations and building units built between 1980 s to 1990 s. The research results can provide references for community and neighbourhood renewal and sustainable development in other residential areas with similar situations. One could predict how to optimise neighbourhood environment by accessing direct sunlight through the experiments in these neighbourhoods. This paper 
targets to generate a new system to assess dense neighbourhood sustainability for daylight performance. It proposes a parametric-based modelling system to simulate and evaluate daylight performance using the dense neighbourhoods in Beijing as examples.

\section{Methods}

A novel parametric-based modelling system allows daylight performance simulation and assessment over a one-year period. It contains two aspects: the input variables, and output models with quantified daylight evaluations. The input variables include geographic location, specified season or date, urban context, and building geometries. These variables are embedded into the constraint script of Grasshopper 3D and Rhinoceros 3D. Through automatic calculation with the parametric software, three-dimensional models with daylight performance are directly presented. The scope of the parametric-based modelling system is to offer a rational insight into how one certain dense neighbourhood can access and use daylight. It helps urban planners, architects, and environmental analysts to quantify daylight access of residential areas and improve the planning and design process with sustainability considerations.

Former researchers use light indicators or sensors to collect daylight data around existing buildings. The manual method could gather relatively accurate information by selecting plenty of samples. However, it normally needs a long time and considerable work-force resource to integrate the collected data and analyse experiment results. To overcome the shortcomings of manual methods, this paper proposes a parametric-based modelling and simulating method taking advantage of algorithmic logic. Grasshopper 3D and Rhinoceros 3D are both parametric tools. They work to edit scripts, build messing models and simulate daylight performance. Grasshopper 3D and Rhinoceros 3D rely upon algorithm logic to create geometry with a visual programming language interface [23]. An algorithm is expressed within a finite amount of space and time and in a welldefined formal language for calculating a function in mathematics and computer science [24]. It starts from an initial state and initial input and describes a computation that, when executed, proceeds through a finite number of well-defined successive states, eventually producing "output" and terminating [25]. Figure 1 presents the daylight performance scripts in the parametric tools in this paper. The scripts are written on the interface of Grasshopper 3D. Then Rhinoceros 3D can effectively present rational models on canvas by editing components and parameter relations in initial states and input. Altering parameters causes changes to propagate throughout all functions, and the geometry to be redrawn [26].

In order to obtain accurate weather data and geographic information, the weather file of the China Standard Weather Database is retrieved from Ladybug. Ladybug is a plug-in for Grasshopper 3D. It allows to import and analyse weather data as well as daylight and shadow studies in the parametric-based modelling system. Year-round weather information such as temperature, humidity, wind speed, and solar radiation is collected and presented in Grasshopper 3D. Figure 2 indicates the foundational data of sensible temperature in Beijing. It is calculated by running the constraint scripts in Ladybug. 




Figure 1. Daylight performance scripts in Grasshopper 3D.

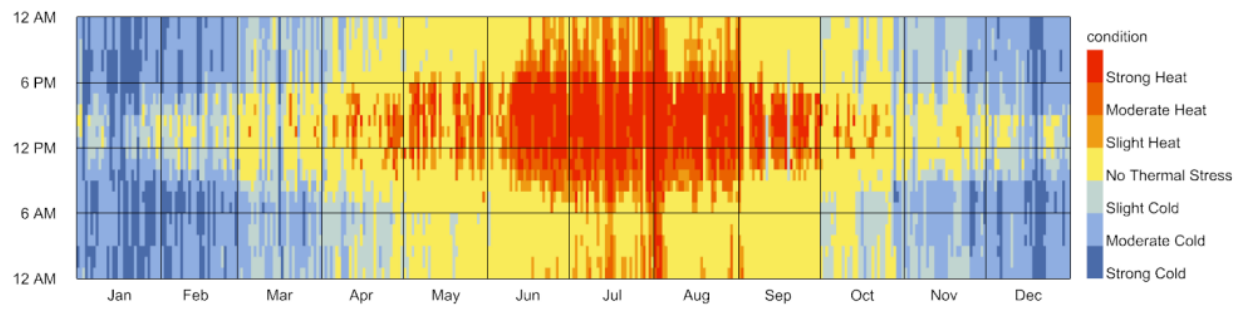

Figure 2. Year-round temperature situation of Beijing, China.

\section{Results and Discussion}

\subsection{Daylight Performance Assessment in Neighbourhood Nanshagou}

Neighbourhood Nanshagou locates at $39.9169^{\circ} \mathrm{N}$ and $116.3265^{\circ} \mathrm{E}$. The general floor area ratio is about 3.2 within a green coverage ratio of $40 \%$. Most residential buildings in this neighbourhood are six-floor. Building layouts present as determinant schema. Seasonal variation in daylight sufficiency analysis is shown in Rhinoceros $3 \mathrm{D}$ (figure 3). For daylight environment assessment, the simulation range is limited as the outdoor space of the residential building cluster. Results indicates that direct sun hours in Neighbourhood Nanshagou are various. The highest sun hour in summer is 15 hours while in winter is 9 hours. Except in summer, there are zones in the neighbourhood share no direct sun light. As the height of the residential buildings increase, the shadow of daylight has been superimposed multiple times. The shadow coverage of the northern part of the neighbourhood is more obvious than that of the southern part. Determinant layout, regardless of the size and height, tends to form shadow for the residence in northern parts. It hardly meets the sufficient daylight demands of the rear rows only by extending distance between buildings. The generation and implementation of dense houses solves the problem of intensive urban land use, while leads to the problem of daylight shading. Shadow interface often affects relatively long distance between multi-level residential buildings. It makes the Isolux Line become complicated. Solar azimuth angle design should be considered to meet the light requirements of the rear and side rows. 

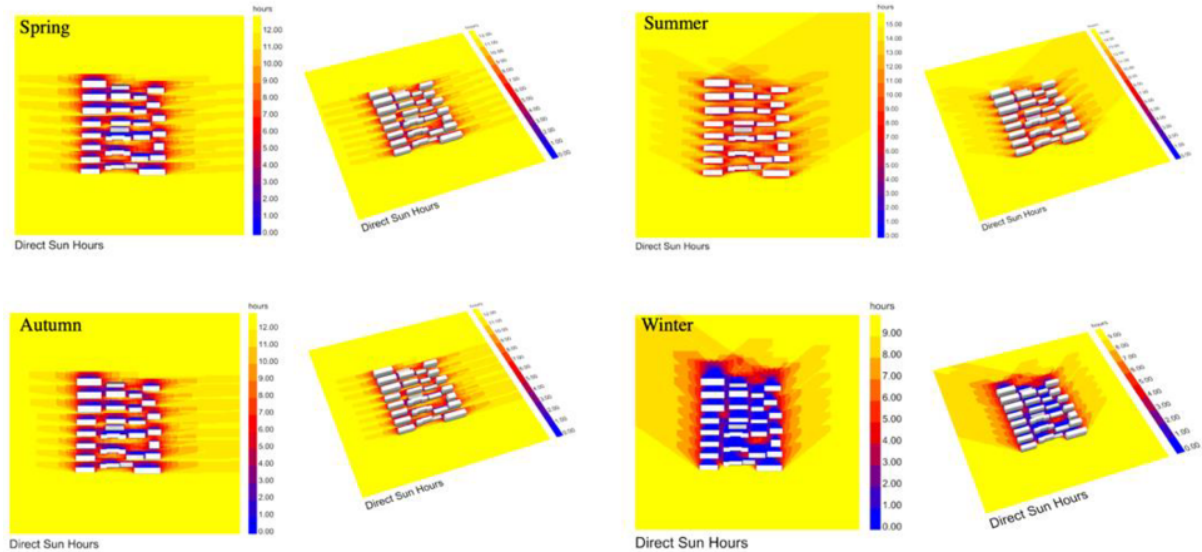

Figure 3. Parametric models and year-round direct sun hours simulation result in Nanshagou.

\subsection{Daylight Performance Assessment in Neighbourhood Huifengtang}

Neighbourhood Huifengtang locates at $39.9088^{\circ} \mathrm{N}$ and $116.3390^{\circ} \mathrm{E}$. The general floor area ratio is about 4.5 within a green coverage ratio of $32 \%$. It is a residential area with a mix of six-floor buildings and twelve-floor buildings. Figure 4 presents the sunlight simulation result. It indicates that high-rise buildings affect daylight access of low buildings particularly in winter. In the peak of summer, shadows offer a natural manner of shading direct light to low temperatures and save energy costs. During cold winter, the blue area is relatively larger compared with other seasons. It means the outdoor atmosphere maybe not that attractive to residents. Multi-layered shadows reinforce low temperature and inaccessible light. Shadows make outdoor space cold and stagnant.

In land-hungry cities, it seems like more and more neighbourhoods contain both high and low residential buildings and houses to meet the requirement of intensive utilisation of urban land. High-rise buildings could bring shadows, which becomes one of the controversies in dense neighbourhoods. Shadows provide shade not just to the pedestrian walking space in hot seasons, but also for communities and neighbourhoods to protect against the heat island effect. Even though, it is generally considered that people intend to access direct daylight as much as possible. Direct sunlight is benefit to the improvement of health, meanwhile decreasing the likelihood of crime and quality of neighbourhood life. Neighbourhood shadows illustrate the paradox of modern dense cities.

\subsection{Daylight Performance Assessment in Neighbourhood Sanlihe}

Neighbourhood Sanlihe locates at $39.9065^{\circ} \mathrm{N}$ and $116.3305^{\circ} \mathrm{E}$. The general floor area ratio is about 4.2 within a green coverage ratio of $37 \%$. Compared with the other two neighbourhood, Sanlihe is a relatively complex residential zone with multi-scale and multi-height residential buildings. The building clusters were built in different years. Problem tends to arise when high-density residential dwellings rise against low-density ones, particularly if they are arranged on the low-density dwellings' southern boundary. The daylight simulation result shows in figure 5. During a year-round period, the northern areas of this neighbourhood covered by shadows mostly. 

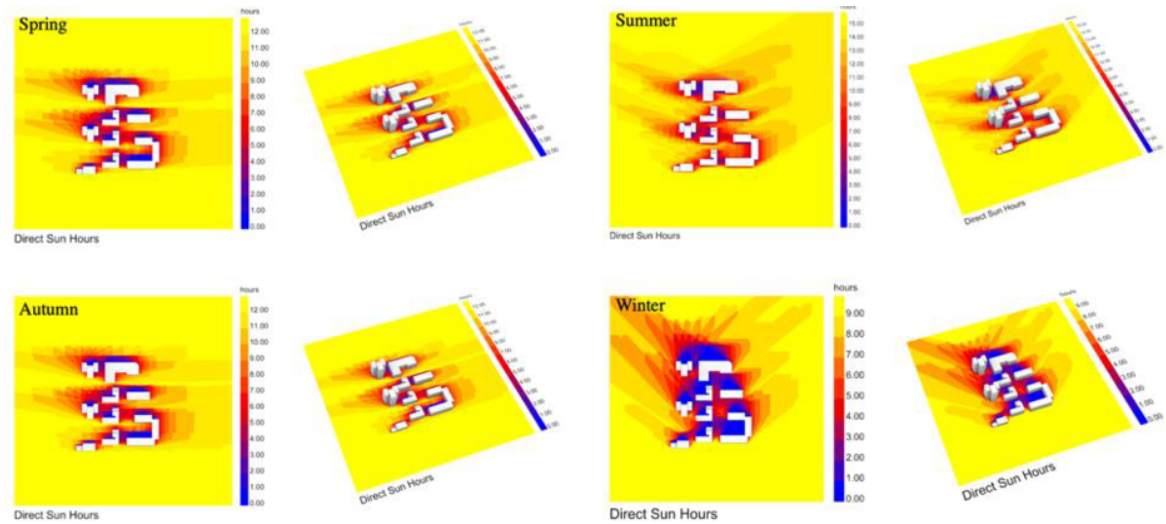

Figure 4. Parametric models and year-round direct sun hours simulation result in Huifengtang.
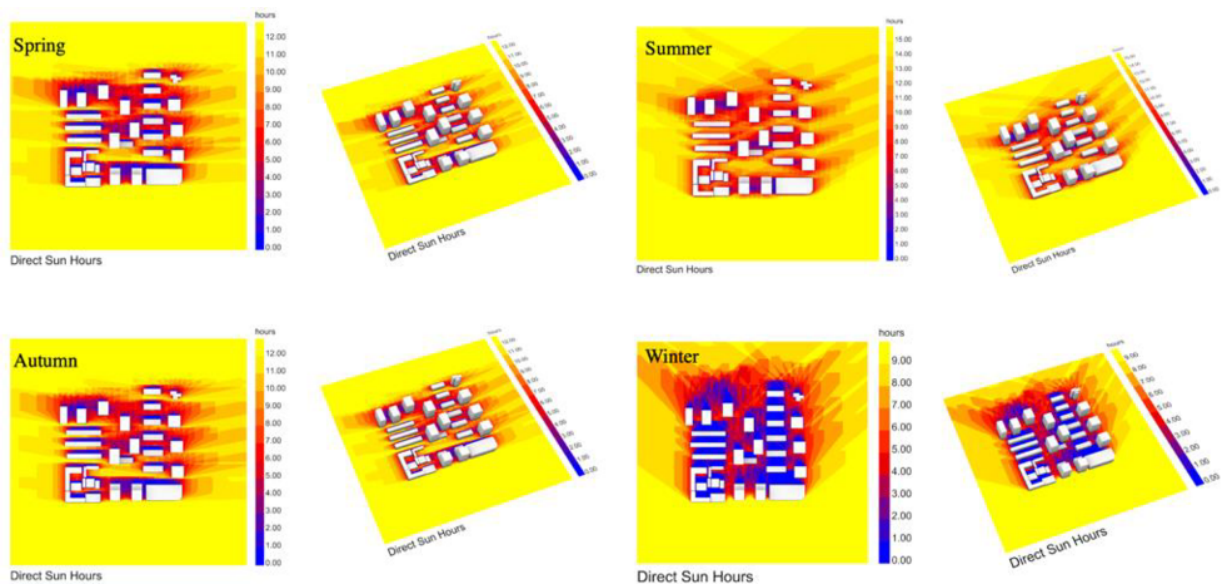

Figure 5. Parametric models and year-round direct sun hours simulation result in Sanlihe.

New planning schema promotes living in high-density communities and neighbourhoods, while increasing density generates conflict between economic land-use development and daylight availability. It relates to residential building geometries, topographic conditions, as well as local policies of daylight access. Conventional zoning mostly provides two-dimensional principles to regulate floor area ratio and text-based index. Parametric-based modelling system provides a novel approach to simulate and assess the daylight available in an effective and practical way.

\section{Conclusions}

Assessing the daylight available to dense neighbourhoods is significant to delivering quality developments in increasingly intensive cities. Towards sustainable urban neighbourhood development, this paper generates a novel parametric-based modelling system for assessing daylight availability in dense neighbourhoods. Parametric techniques and tools have been embedded into the daylight evaluation process. It captures quantified sunlight hours in multiple residential building clusters. Furthermore, 
it simulates the shadow layers during a year-round period to evaluate outdoor space quality that allows urban planners, architects and environmental analysts to optimise daylight performance. Findings are drawn from experiments in sample neighbourhoods in Beijing. The research question has been addressed that parametric techniques can support not only daylight performance evaluation effectively, but also sustainable land use zoning and energy saving in dense urban areas.

\section{References}

[1] Department of Economic and Social Affairs, United Nations 2015 World Urbanization Prospects: the 2014 Revision, pp 21-36.

[2] Wendell Cox Consultancy 2020 Demographia World Urban Areas. Belleville, Illinoise: World Agglomeration.

[3] Berghauser P M and Haupt P A 2009 Space, Density and Urban Form (Delft: Delft University of Technology).

[4] Rapoport A 1975 Toward a redefinition of density Environment and Behaviour 2 (7) 133-158.

[5] Cheng V 2009 Understanding density and high density.Designing High Density Cities (London: Earthscan).

[6] Crawford J H 2000 Carfree Cities (Charlbury: International Books).

[7] Alexander E R 1993 Density measures: A review and analysis Journal of Architectural and Planning Research 10 181-202.

[8] Stokols D 1972 On the distinction between density and crowding: Some implications for future research Psychological Review 79 275-277.

[9] Chan Y K 1999 Density, crowding and factors intervening in their relationship: Evidence from a hyperdense metropolis Social Indicators Research 48 103-124.

[10] Corrodi M and Spechtenhauser K 2008 Illuminating: Natural Light in Residential Architecture (Basel London: Birkhäuser $\mathrm{GmbH}$ ).

[11] Rockcastle S and Andersen M 2013 Celebrating contrast and daylight variability in contemporary architectural design: A typological approach Proceedings to LUX EUROPA (Krakow, Poland).

[12] Gherri B 2015 Assessment of Daylight Performance in Buildings: Methods and Design Strategies (Southampton: WIT Press).

[13] Webb A R 2006 Considerations for lighting in the built environment: Non-visual effects of light Energy and Buildings 38 (7) 721-727.

[14] Li D H W and Lam J C 2000 Measurements of solar radiation and illuminance on vertical surfaces and daylighting implications Renewable Energy 20 (4) 389-404.

[15] Akin O and Moustapha H 2004 Strategic use of representation in architectural massing Design Studies $2531-50$

[16] Kvan T and Thilakaratne R 2003 Models in the design conversation: Architectural vs. engineering Proceedings of Asian-American Association of School Administrators Conference (USA).

[17] Agarwal M, Pastore L and Andersen M 2017 Suitability of neighborhood-scale massing models for daylight performance evaluation Proceedings of International Conference on Sustainable Design of the Built Environment (London, UK).

[18] Raphael B 2011 Active control of daylighting features in buildings Computer-Aided Civil and Infrastructure Engineering 26 (5) 393-405.

[19] Compagnon R 2004 Solar and daylight availability in the urban fabric Energy and Buildings 36 (4) 321328.

[20] Neufert E and Neufert P 2012 Neufert Architects' Data 4th edition (Chichester, West Sussex, UK; Ames, Iowa: Wiley-Blackwell).

[21] Chartered Institution of Building Services Engineers 2013 Lighting for Communal Residential Buildings$L G 9$.

[22] Dogan T and Park Y 2017 A new framework for residential daylight performance evaluation Proceedings of Building Simulation 2017 (San Francisco, USA).

[23] Reilly C 2014 What is Grasshopper? Retrieved June 202017 from https://www.lynda.com/Grasshoppertutorials/What-Grasshopper/174491/194087-4.html.

[24] Rogers H 1987 Theory of Recursive Functions and Effective Computability (Massachusetts: The Massachusetts Institute of Technology Press). 
454 Y. Zhang and Y. Ning / Assessing Dense Neighbourhood Sustainability for Daylight Performance

[25] Knuth D 1969 Semi-numerical Algorithms: The Art of Computer Programming (Massachusetts: Addison Wesley).

[26] Davis D 2013 A History of Parametric Retrieved July 182017 from http://www.danieldavis.com/ahistory-of-parametric/. 